\title{
A Nova Babilónia ou a rua como um happening non-stop de comprido
}

New Babylon or the Street as Non-stop Happening

La nouvelle Babylone ou la rue comme un happening non-stop

\section{Pedro Pousada}

\section{OpenEdition}

\section{Journals}

Edição electrónica

URL: http://journals.openedition.org/rccs/5152

DOI: $10.4000 /$ rccs. 5152

ISSN: 2182-7435

\section{Editora}

Centro de Estudos Sociais da Universidade de Coimbra

\section{Edição impressa}

Data de publição: 1 Dezembro 2012

Paginação: 167-184

ISSN: 0254-1106

\section{Refêrencia eletrónica}

Pedro Pousada, "A Nova Babilónia ou a rua como um happening non-stop de comprido », Revista Crítica de Ciências Sociais [Online], 99 | 2012, colocado online no dia 04 setembro 2013, criado a 01 maio 2019. URL : http://journals.openedition.org/rccs/5152 ; DOI : 10.4000/rccs.5152 


\title{
PEDRO POUSADA
}

\section{A Nova Babilónia ou a rua como um happening non-stop de comprido}

\begin{abstract}
Este artigo discute a Nova Babilónia, a metacidade desenvolvida num período de quase vinte anos (1953-56/1974) por Constant Nieuwenhuis (1929-2005) e apresenta argumentos para que seja lida como uma variante de agit-monumento, uma manifestação da antiarte pública e antioficial, que se ergue contra a desvalorização quotidiana do "conhece-te a ti próprio", contra o facto de a vida moderna exortar cada vez menos os homens à vida filosófica, à consciência crítica, a atuarem politicamente para mudarem as suas condições sociais.

Entendemos aqui a Nova Babilónia, a superurbe situacionista, como uma sociedade sem espetáculo mas na sua essência comunitária, como o lugar histórico onde o contraste entre o existente e o possível é superado.
\end{abstract}

Palavras-chave: arquitetura; cidades; contracultura; cultura; Nova Babilónia.

A cidade é a hiper-realização do século xx, como na colagem de Paul Citroen, Metropolis (1923); ela revela-se uma "tatuagem móvel", ${ }^{1}$ quebradiça e indecifrável; uma acumulação incompreensível de sistemas abstratos onde a estética tecnopastoral, a aura heroica, positiva, da industrialização se dissipa diante daquilo que criou: uma superfície onde se contrastam irracionalidade e produção, divisão social do trabalho e mobilização individual, acaso e controlo social, planificação do real e isolamento das comunidades; uma enorme máquina que se baseia no esquecimento e no eterno retorno.

Charles Baudelaire antecipa essa condição material da modernidade ao observar a competição crescente entre os campanários das igrejas e as chaminés fumegantes das fábricas. O tempo sagrado e o horário industrial entrelaçando-se numa luta desigual em que já não há relação narrativa entre o espaço público e o edificado, em que os aspetos improdutivos da cidade

1 "O sangue da noite moderna é uma luz cantante. Tatuagens, ela tem tatuagens móveis no seu seio, a noite” (L. Aragon, 1982: 173). Tradução do autor do artigo. 
vão sendo socializados como uma menor valia para a lógica carrefourista e para o belo enquanto mercadoria económica.

$\mathrm{Na}$ cidade moderna a viagem do indivíduo, a sua construção identitária, realiza-se sob o óbice da estranheza, da novidade espacial superada, do trânsito monetário encarnado no eterno retorno da rua de comprido, lugar de insónia onde a logística distribui, as montras sensualizam e os transeuntes rastreiam as suas falsas necessidades.

Não nos faltam ecos contemporâneos da representação baudelairiana do estar vivo e de se existir numa cidade (e os Rastignacs, Gregor Samsa e Franz Biberkopf deste mundo são disso testemunhas); essa itinerância, esse pressentimento das "ordens e desordens dinâmicas" (Gordon Matta-Clark apud Attlee, 2007) do espaço urbano, a experiência da cidade como um oximoro é reiterada por Jean-Luc Nancy, que salienta que o objeto civilizacional, cidade, não é um objeto civilizado. ${ }^{2}$

Esta é a cidade concreta, um objeto cinético onde o reino da liberdade joga às escondidas com o colete de forças do reino da necessidade, onde o indivíduo é uma acumulação complicada de factos biográficos e de matrículas burocráticas, um número, uma referência, uma genealogia, um cidadão mão de obra, um cidadão sapiens, um desempregado, um veterano de coisas de que não se quer lembrar, de alegrias que não voltarão a repetir-se, de amores à última vista; o lugar onde o indivíduo é essas coisas todas e ao mesmo tempo tenta organizar-se no caos, definir um mapa, determinar uma posição, ocupando e valorizando, para isso, os terrenos baldios do convívio humano.

Tentaremos falar aqui de um desses indivíduos e da sua cidade imaginada, uma cidade que ficou conhecida por Nova Babilónia e que hoje existe apenas como arquivo e memória do poder da imagem, uma cidade-projeto desenhada e "esculpida" pelo artista Constant Nieuwenhuis (1929-2005), onde o nonsite e a experiência autobiográfica se converteram num estilo de vida, melhor dizendo, numa metacidade.

Constant Nieuwenhuis tinha 36 anos quando as suas ideias e orientações sobre o que viria a ser a sua principal, mais prolongada (vinte anos de acumulação pitoresca) e consequente investigação artística e prática, (chamemos-lhe mesmo laboratorial) amadureceram na forma urbana da Nova Babilónia: a discussão filosófica sobre o tipo de ligação possível entre o modo de vida e o ambiente construído culminou na conceção de uma cidade diferente, um oximoro urbano duplamente tecnocrata e

\footnotetext{
2 "La ville n'est pas civilisée, elle est bien plutôt le cœur agité, la montée et l'assaut de la civilisation [...]" (Nancy, 1999: 44).
} 
antiutilitarista; um projeto situado num nível intermédio de intervenção arquitetónica, num "nível macro-arquitetónico e micro-urbanístico"3 como o descreverá mais tarde Henri Lefebvre, um projeto que se subsidiou do pensamento situacionista e por sua vez o fomentou e desenvolveu. ${ }^{4}$

É necessário, para prosseguirmos, esclarecer o que neste contexto se designa por metacidade. O termo tem-nos servido 5 para colocar sobre um guarda-chuva conceptual cidades-objeto, cidades autorreferenciais, que não existem, que nunca existiram, cujo assunto principal é a própria ideia de cidade. A metacidade é, acima de tudo, um objeto "anfiónico" (recuperando um termo inventado por Guillaume Apollinaire ${ }^{6}$ para descrever um objeto onde a arte entra na vida e constrói a vida através da cidade), um objeto cujas vantagens pertencem em exclusivo ao seu criador-utilizador; uma superestrutura em que o ethos arquitetónico se autorrepresenta como um projeto e um ativismo social; um espectro de comunidades fictícias que se instalam (como memória, como dilação) na fronteira entre a pesquisa da vanguarda (artística, política), entre o pretendido e o realmente construído e conseguido; "um quadro de vida total" (Kopp, 1990: 74) que pretende essencializar o que

\footnotetext{
${ }^{3}$ Consulte-se o capítulo Espace et Politique em Le droit à la ville de H. Lefebvre (1972: 256-270) e a entrevista que deu a Kristen Ross em 1983 e que seria republicada pela revista norte-americana October (N. ${ }^{\circ}$ 79, dezembro, 1997). A análise de H. Lefebvre sobre a cidade moderna, sobre a cidade da época social do capitalismo monopolista, recordam-nos que ele não só partilhou algumas das hipóteses da teoria urbana do radicalismo situacionista, como foi num período relativamente curto mas produtivo, um colaborador activo ainda que institucional (era investigador no C.N.R.S.) desse movimento.

${ }^{4}$ Desde as suas reuniões fundadoras que a Internacional Situacionista debateu a necessidade de encontrar instrumentos de acção directa, capazes de estabelecerem um ponto de contacto entre a práxis global em que se dissolverão todos os aspetos da vida total na sociedade sem classes e a realidade presente, onde predomina a prática individualizada na vida privada com os seus pobres recursos artísticos e outros. O divórcio, a antinomia programática, entre as práticas políticas radicais, a esquerda revolucionária, e as vanguardas artísticas é outro dos temas recorrentes e amplamente discutidos. É nesse aspeto que nas suas análises sobre o problema cultural, (sobre a incapacidade da revolução simbólica de a arte resolver a natureza reificada da vida particular, da vida produzida pelo mundo do trabalho) procede a uma crítica política do modernismo, em particular de uma versão setorial e administrativa de modernismo (de gestão controlada e repetitiva dos seus ganhos históricos). Três textos condensam o essencial do pensamento situacionista sobre a questão artística: Teses sobre a Revolução Cultural (Internationale Situationniste, junho, 1958), A ausência e os seus clientes (Internationale Situationniste 2, dezembro, 1958) e O sentimento de decadência da arte (Internationale Situationniste 3, dezembro, 1959), na revista October (N. ${ }^{\circ}$ 79, dezembro, 1997. Cambridge, MA: MIT Press: 99-107).

5 Pedro Pousada (2009), A arquitetura na sua ausência. Coimbra: Tese de Doutoramento apresentada ao Departamento de Arquitetura da Universidade de Coimbra - Darq.

${ }^{6}$ No seu livro de contos O beresiarca \& C. ${ }^{a}(2008)$, mais precisamente no conto "Anfião, o falso messias ou histórias e aventuras do Barão d'Ormesan” (2008: 175-178), Guillaume Apollinaire coloca-nos diante de um anti-herói moderno que reclamava para si a invenção de uma arte "sui generis, baseada no peripatetismo de Aristóteles" e a que chamaria de "anfiónia", em referência a Anfião, filho de Júpiter e Antíope, que segundo a mitologia grega teria edificado com o som da sua lira parte da cidade de Tebas.
} 
é e o que faz uma cidade, que assume como vocação enumerar, antologizar, miniaturizar as condições materiais, sociais, económicas, culturais que permitem que uma experiência coletiva, uma experiência comunitária, adquira uma forma espacial; que a definem como uma combinação (ou uma homogeneização forçada) de diferenças: aqui uma grelha geométrica de ruas, um fluxo de vida e de mercadorias onde desaparecem as contradições entre o surplus e o açambarcamento, entre a crise e a ordem securitária; o culminar feliz da organização logocêntrica, a arte de viver adaptada à visualidade cubomórfica; ali uma "floresta de símbolos", 7 o movimento asfixiado entre a velocidade e a afasia, a vida privada a avançar para a ruína, para o esquecimento. A cidade como intensificação e heroificação da vida produtiva e da vida política. Noutro lado é a organização ludocêntrica e a automatização que liquidam os limites entre trabalho e prazer, que introduzem o improdutivo, o descanso, o passeio, a festa (a cidade como um gigantesco potlach), é a cidade vista como um oceano de aventuras, diversões, atualizações, insegurança e surpresas permanentes, a cidade à espera dos seus náufragos-jogadores mesmo que eles desconheçam a sua condição de náufragos e de jogadores.

A metacidade que faz parte desta nossa reflexão existe sobretudo por via dos seus significantes (das maquetas, dos desenhos, das fotomontagens, dos diagramas e das declarações escritas do seu autor e apologistas) já que os seus significados nunca se fecham na totalidade, nunca ficam, de facto, esclarecidos ou porque o demasiado pequeno (as condensações e minúcias da repetição quotidiana, da vida doméstica e da vida privada) é posto numa situação indefinida, intermitente, sendo continuamente transformado no efeito esperado da ação e da presença do demasiado grande, do progresso panóptico que vê e age sobre tudo; ou porque a aparente duração das suas formas arquitetónicas, a falsa (e impossível) eternidade da sua gestalt é de facto uma mentira estética: se a cidade utópica fosse a representação do progresso ela teria o rosto da morte.

O pensamento de Constant Nieuwenhuis sobre a cidade moderna situa-se na esquerda política da produção artística modernista mas pertence a uma história diferente da cultura construtivista/produtivista e a uma fase avançada e já em crise da lógica vanguardista. Constant, não só pertence à cronologia da recomposição político-económica da Europa Ocidental, como a sua migração ativista - por movimentos como o grupo CoBrA, a Internacional Letrista, a Internacional Situacionista e o espírito de incompletude dessa presença -

\footnotetext{
7 Referência ao poema "Correspondances" de Charles Baudelare: "La Nature est un temple où de vivants piliers/Laissent parfois sortir de confuses paroles;/L'homme y passe à travers des fôrets de symboles/Qui l'observent avec des regards familiers" (1996: 37).
} 
nos permite observar a crise estrutural do heroísmo de vanguarda no seu estado cinético. Essa crise, ainda que multifatorial, tem a sua matriz no impasse a que chegara o debate sobre o valor concreto do campo artístico na luta social e a capacidade real ou não que demonstrava em constituir uma crítica à partição abstrata e unidimensional da vida quotidiana; em ser ou não uma resistência às inércias que colocam sem aparente salvação todas as formas de existência e de criatividade humana, assim como os seus princípios éticos, o amor, a estética, o conhecimento, a educação, a saúde na corrente monetária da troca e do lucro.

$\mathrm{Na}$ década em que Constant inicia o seu projeto a consciência de uma separação possui contornos definidos; o desenlace do Modernismo heroico numa pós-vida duplamente empírica e técnica, isto é, a sua imersão total na vida prática, na empiria das coisas e das necessidades quotidianas, não se concretizou; a arte permanece como um objeto marginal à vida quotidiana e sem poder ou disposição programática para agir sobre ela, essa separação intensificou, por sua vez, uma contradição da evolução interna do Modernismo; quanto mais este se tentava afastar do regime ótico e das convenções disciplinares de cada uma das suas manifestações materiais, maior era a hegemonização e institucionalização da autonomia e tecnocracia artística.

O desvio já observado por André Breton no segundo Manifesto Surrealista (1930) entre as vanguardas políticas e as vanguardas artísticas torna-se, senão irreversível, pelo menos irresolúvel. Na sua Ode a Fourier (1945-47), Breton sintetiza com uma tristeza reveladora o que estivera em jogo: "[Fourier] Só falavas em ligar tudo e vê: tudo se desligou" (Breton, 1994: 101). A crise sistémica entre "popularização e especialização" (Habermas, 1987: 5-23), entre práxis quotidiana intersubjetiva e a ação instrumental, diretiva impessoal do mundo político e económico (utilizando termos caros a Jürgen Habermas), não fora resolvida pela contracultura artística das vanguardas.

É esta resiliência, (esta dificuldade em conciliar a esfera artística com a vida prática para além do plano funcionalista, da antecipação tecnocrática e utilitarista) que catalisa a experiência de Constant em torno da ideia de cidade; o espaço, a sua alienação pelo tempo, a sua organização, a questão fundiária, a estética e a política dos objetos que o habitam, os modos de viver das comunidades que o humanizam, são problemas concretos, são problemas onde a vontade artística pode prolongar o seu antagonismo de reação em relação ao poder dos administradores, pode de facto contrariar as expectativas de controlo social, sobrepondo a originalidade do processo à obediência da finalidade. 
Ao mesmo tempo que se propunha corrigir passo a passo o subdesenvolvimento contraditório da vida quotidiana integrando-a, inclusivamente, numa nova técnica de consumo espacial - a deriva psicogeográfica e convertendo as propriedades mortais da civilização industrial em sirenes de um programa ambicioso de resistência à regulação utilitária, sem encarniçamentos ou inquietações existenciais, do espaço urbano, a Nova Babilónia oferece-nos uma resposta verosímil a essa pergunta histórica que atormentou mais de meio século de Modernismo: para que serve a arte?

A ontologia deste projeto, e em particular os elementos subjetivos e objetivos que levaram Constant a interessar-se por conceber uma cidade baseada num novo modo de produção urbana, têm um início quotidiano. Diz-nos Roland Barthes que a utopia "enraíza-se num certo quotidiano. Quanto mais o quotidiano de um indivíduo é premente (sobre seu pensamento) mais a utopia se torna forte, (minuciosa)" (2002: 35). Numa entrevista conduzida por Linda Boersma, talvez a sua última, publicada na Bomb Magazine \#91, Constant refere a sua estadia em Frankfurt no ano de 1951 na companhia do seu filho e a premência desse quotidiano. Descreve uma cidade ainda atingida pelos efeitos do carpet bombing aliado e afirma:

se atravessamos uma cidade em ruínas então a coisa mais natural que podemos pensar é em construir; e se reconstruímos essa cidade então é provável que nos interroguemos se a vida nela continuará a ser igual ao que fora ou se será diferente. Depois pensa-se na influência do contexto, daquilo que rodeia essa cidade. (2005)

Entre 1948 (ano ontológico para o grupo CoBrA) e a sua separação do grupo situacionista, 1960, o quotidiano de Constant incorporou-se em pequenas mas aguerridas comunidades artísticas, coabitando e trabalhando coletivamente, ocupando espaços devolutos ou semiabandonados, frequentando espaços de boémia e de diversão noturna semiclandestinos, participando em festivais internacionais, erguendo projetos de vivência nómada; incorporou-se numa cultura dissidente que na sua fisicalidade, na sua mortalidade metabólica (o sigamos em frente! de Breton transformado num tática de sobrevivência), na refundação da autonomia artística através da crítica do espetáculo, na sua colagem entre ativismo político e vida quotidiana (na recusa da separação e imobilidade dessas duas esferas da experiência humana) concretizava o mote que Constant foi buscar a Rimbaud para explicar o détournement antropológico da sua cidade: 
"chegar ao desconhecido pelo desregramento de todos os sentidos". ${ }^{8}$ A humanidade comemorada por Constant é resultado desse enraizamento e ao mesmo tempo tem um carácter pós-diluviano, isto é, de renascimento, de reencarnação (já não apenas do indivíduo isolado, empenhado na sua super-heroificação pessoal, mas de comunidades inteiras de indivíduos).

$\mathrm{Na}$ segunda metade da década de cinquenta, o artista visual Constant até então associado ao neoprimitivismo do grupo $\mathrm{CoBrA}$ reinventou-se como arquiteto. Esse processo iniciou-se com a colaboração e o convívio profissional com Aldo van Eyck, que o introduziu na jovem e heterodoxa comunidade arquitetónica de Amesterdão; estudou arquitetura por sua própria iniciativa e em particular as técnicas e os materiais construtivos contemporâneos, participou em grupos de discussão arquitetónica, polemizou, tomou posições, integrou-se na secção holandesa da corrente adversária do modernismo clássico definido por Le Corbusier e secretariado por Gideon nos CIAMs anteriores a 1939, participou em parceria com Rietveld na conceção de módulos habitacionais exibidos em feiras de design e de mobiliário (terá Constant conhecido o apartamento por cima do Vreebug Cinema em Utrecht que Rietveld desenhou em 1929 e onde este vivia com a sua família num open space sem divisórias fixas e com cortinas a separarem a família apenas durante a noite?). De acordo com a cronologia fornecida por Mark Wigley (2001: 142-144), os seus primeiros desenhos datam de finais da década de 50. Segundo essa mesma cronologia, Constant e Guy Debord estabelecem os primeiros contactos em 1956, assinando coletivamente alguns textos sobre a cidade antifuncionalista; mas será só em 1959, já depois dos primeiros desenhos e maquetes serem expostos no Stedelijk Museum, que o nome da cidade bíblica (a némesis, na cultura hebraico-cristã, de Jerusalém, a cidade de Deus) faz a sua entrada por sugestão de Debord, sendo até essa altura referida por Constant como Dériville ("cidade da deriva”).

Os três lugares físicos, que assinalam a saída da sua reflexão da encruzilhada conceptual e o encontro de uma resposta duradoura à necessidade dialética de a cor (a pintura) e a forma (a arquitetura) funcionarem num sentido cooperante, são i) Alba, em Itália, mais especificamente o Congresso do Movimento Internacional por uma Bauhaus Imaginista (1956) onde conheceu e iniciou a sua colaboração com Guy Debord; ii) Cosio d'Arroscia, onde participou na fundação do grupo Internacional Situacionista e iii) a sua Amesterdão natal, que serviu de plataforma para um documento essencial

\footnotetext{
${ }^{8}$ Rimbaud apud Constant, New Babylon (Catálogo da exposição). Haia: Haags Gemeentemuseum, 1974: 46-63. Rimbaud apud Hilde Heynen (1996: 27).
} 
ao entendimento da génese do seu projeto, "A declaração de Amesterdão", assinada com Guy Debord e onde se problematiza a ideia de um urbanismo unitário, a primeira forma ideológica, posicional da cidade ludens.

O fim do Nazifascismo tinha sido apenas há 11 anos e a Europa ainda recuperava das suas feridas físicas e morais. Sete anos antes a Holanda, de onde era natural, reconhecera a independência da sua antiga colónia do sudeste asiático, a Indonésia, após uma sangrenta guerra de quatro anos (1945-49). Fazia um ano que na conferência de Genebra a França cessara as suas pretensões coloniais sobre o território da Indochina. Ainda persistiam as colónias europeias em África e a guerra da Argélia ia no seu segundo ano. Os bantustões (o Homeland Act de 1951) eram a mais recente invenção geopolítica dos racistas africânderes para suburbanizar a população africana de acordo com origens tribais, mantendo-as separadas do desenvolvimento urbano branco e ao mesmo tempo ao seu alcance como mão de obra barata. O massacre de Sharpeville (1960) ainda não ocorrera nem as Nações Unidas tinham isolado o regime do Apartheid (1962). A crise do Suez (a nacionalização do canal e a consequente agressão tripartida) ocorreria nesse mesmo ano. E esse é também o ano da exposição itinerante "Modern Art in the U.S." que apresentará a um público europeu os cinquenta anos do modernismo norte-americano de Max Weber a Mark Rothko com destaque para Jackson Pollock, Robert Motherwell, Clifford Still e Franz Kline. Depois do desembarque em 1950 pela mão de Alfred Barr das tropas de choque do Expressionsimo Abstracto na Bienal de Veneza, uma espécie de inversão da experiência do Armory Show de 1913, esta seria a segunda operação em que a cultura artística de vanguarda made in U.S.A serviria como utensílio de agit-propaganda, inaugurando-se com a tomada do reduto original do modernismo europeu, Paris, e seguindo até Londres, Barcelona, Zurique, Frankfurt e Haia. É provável que estes factos, a sua experiência passada ou a premonição de acontecimentos futuros, não moldassem as conversas ou as expectativas dos membros do Congresso de Alba, mas de certo modo ajudam-nos a entender o contexto em que se iniciam os trabalhos de Constant. Quando deu por terminado esse investimento, em 1974 pouco tempo depois do choque petrolífero, Constant era um homem de 54 anos.

Nos dezoito anos que transcorreram a decisão de se ocupar sobre a organização especulativa de um novo modus vivendi urbano, o empreendimento pictórico, gráfico, maquetista adquiriu uma mais-valia teórica e mediática - em 1959 e 1960 as primeiras publicações na Internacional Situacionista n. ${ }^{\circ} 3$ e 4, no mesmo ano de 1960 a apresentação pública no museu Stedelijk de Amesterdão, em 1962 aparição em programas de televisão, em 1963 uma 
edição de dez litografias acompanhadas de um texto de Simon Vikenoog, "Nova Babilónia, preâmbulo para um novo mundo", em 1966 a produção de um filme sobre a Nova Babilónia.

Olhar crítico sobre a "cidade da pesquisa moderna", sobre as polaridades cada vez mais distópicas da Carta de Atenas de 1933, (assim como dos seus subtextos) que colocavam o funcionalismo cada vez mais na esfera mítica e acentuavam a divergência entre uma teoria das cidades da liberdade enciclopédica e uma prática de cidades prêt-a-porter, monofuncionais e unidimensionais; crítica à colagem de taylorismo e de saint-simonismo do pensamento corbusiano, o projeto de Constant não é contudo um exercício agonista, utilizando, pelo contrário, em benefício da gestalt temporária "da sua história infinita de transformação" (McDonough, 2001: 97) os resultados conseguidos e as possibilidades desencadeadas por essa mesma investigação. É um inquérito com uma dimensão antropo-ética que se prestou (e ainda se presta) a muitas doxografias. Constitui como já vimos uma revisão, também, dos valores da modernidade artística e política, identificada como uma presença incompleta, frugal, ainda demasiado preambular, na aparência quotidiana das cidades e dos espaços urbanos realmente existentes. A tensão temática e construtiva desta experiência de laboratório (um espaço diferente onde os homens podem fugir de si mesmos, onde existem saídas de emergência para a vida quotidiana, onde, pelo menos é essa a tese plástica de Constant, os mecanismos reguladores não se sobrepõem à imaginação criativa) não deixa de se integrar no espírito de recentramento do espaço público com que os CIAMS do pós-guerra (Constant será um dos participantes do CIAM de 1953) e as dissidências heterodoxas do modernismo arquitetónico tentam reformular a discussão do pensamento arquitetónico e urbano do Movimento Moderno; e de certa forma, a dialética entre uma espinha dorsal predeterminada e a autorregulação, a possibilidade da fluidez e estranhamento formal, do quase ecletismo, a sobredeterminação do desejo dos habitantes como princípio orgânico da construção, incorpora a cidade de Constant na ideologia arquitetónica, no weltgeist de projetos como a Plug-in City (1964) dos Archigram, as cidades metabólicas da arquitetura moderna japonesa, a nova Tokyo de Kenzo Tange (1960). Por outro lado a Nova Babilónia reage à nova haussmanização continental, que já não se realiza em nome do carrefourismo, da cristalização da cidade em cenário do bem-estar burguês, mas em proveito de um tipo de condicionamento onde as novas comunidades, os "quartéis civis" da não participação, são instrumentos eficazes e duráveis. Como iluminação e contradição profana que consegue ser, a Nova Babilónia é por sua vez uma testemunha indireta das mudanças graduais mas profundas que se estavam a operar 
na economia capitalista: o desenvolvimento desigual do pós-fordismo no mundo industrializado é uma das sombras ideológicas que se projetam sobre esta comunidade antifuncionalista. Já em 1959, numa contribuição para a revista Internationale Situationniste, Constant descreverá esta megaestrutura futura de acordo com o que já era possível presenciar e conceber na realidade que lhe era imediatamente contemporânea: "o uso inventivo das condições materiais, como o ar condicionado, o som e a luz. Uma cacofonia harmonizante... viagens espaciais... redução do trabalho necessário para a produção... máximo de espaço social” (A. Vidler, 2001: 89). E testemunha também o que isso significará em termos de alteração dramática na escala e na qualidade das forças produtivas, na crescente diminuição do papel da fábrica como espaço do trabalho humano, na separação definitiva, via automatização, do homem em relação ao produto finalizado, na inversão do processo que levou às grandes demografias de mão de obra intensiva (é o lento começar da morte das cidades industriais), na penetração do desenvolvimento científico e tecnológico em todas as esferas da atividade humana desde o consumo, o lazer, a cultura, a educação, passando pelos transportes, os serviços de saúde e o turismo. ${ }^{9}$

A metacidade de Constant entrevê-se, então, como uma enorme coleção de diagramas que relacionam as contribuições do Surrealismo acerca da cidade e a sua defesa de uma antiarquitetura; a análise sociológica desenvolvida por Henri Lefebvre em torno da vida quotidiana e da organização e planeamento das cidades contemporâneas; o maquinismo cibernético de arquitetos como Buckminster Fuller e a sua própria experiência pessoal enquanto colaborador do arquiteto holandês Aldo van Eyck, como membro do grupo dirigido por Yonna Friedman e como ativista e teórico do urbanismo situacionista desde a publicação em 1953 do seu texto Pour une architecture situationniste. É aliás Anthony Vidler (2001: 88-90) quem relaciona o projeto de Constant com a tradição moderna do diagrama e, nesse contexto, com a prática iluminista de maquinização do espaço. Apoiando-se no texto de Roland Barthes, Sade, Fourier, Loyola, A. Vidler refere alguns exemplos dessas instituições utópicas - o Asilo da Lubricidade, o contra-panóptico imaginado pelo Marquês de Sade no seu 120 dias de Sodoma e o palácio-falanstério de Fourier - lugares onde a incompletude, o carácter mutante e impreciso da "organização de um edifício e de um território",

\footnotetext{
${ }^{9}$ Sobre este tema, leia-se o que o filósofo checo Radovan Richta escreve no seu Revolução científica e técnica e transformações sociais $(1973: 25-27,39)$. Um texto que é aliás contemporâneo das preocupações do urbanismo unitário e onde a reorganização espacial e antropológica da cidade histórica europeia, assim como edificação das futuras cidades, se prefigura em moldes muito próximos da metacidade de Constant.
} 
a sua fusão numa única coisa, a cidade-edifício, subalternizam, colocam em segundo plano os desempenhos abstratos da arquitetura e do urbanismo em relação a uma "ciência geral do lugar humano" (Barthes, 1979: 112). $\mathrm{Na}$ sua duplicidade de macroestrutura fixa, monumental e pesada mas também de tábua sem memória, baseada numa estética do provisório e do presencial, a Nova Babilónia reflete esse carácter de "ciência geral do lugar humano”. É uma organização extremamente complexa e difusa que assenta na oferta tecnológica da arquitetura moderna (a sustentação da cidade-edifício baseia-se nos pilotis corbusianos mas também em todo o tipo de sustentação mecânica desenvolvida pela engenharia da época) para se colocar por cima (e não sobre) a cidade antiga. Quase que a poderíamos associar ao modelo das cidade-pontes tratando-se, contudo, de uma cidade confinada sobre si mesma e deslocando-se paralela à cartografia do existente.

Os significantes arquitetónicos, as maquetes e as representações fotográficas, com que Constant parece solucionar em termos de aparência exterior e de macroestrutura o seu hapenning non-stop, baseiam-se na ideia de construção, na soma de partes tectónicas, na combinação de materiais e de maquinaria de vanguarda, na criação técnica de espaço contido, de vazio, no trespasse clássico e revelador da luz sobre as formas, da luz separando e "diferenciando o pilar vertical da plataforma horizontal" (Krauss, 1994: 168), em síntese, baseiam-se na presença e supremacia da forma, na relação hierarquizada entre exterior e interior, cheio e vazio, alto e baixo (ainda que Constant pretenda resolver isso por via antropológica, isto é, alterando e subvertendo os hábitos da vida quotidiana que se ingressam nesses dois territórios, socializando a priori o uso e a mediatização do espaço). E era a esta evidência que queríamos chegar: à contradição produtiva (que Constant explora e assume como essencial), entre a exterioridade arquitetónica desta utópica "economia do viver", entre a forte visualidade formalista, entre o carácter estável do invólucro, dizíamos, e a natureza informe, indefinida do seu interior. Do lado de fora, a arquitetura é produto de adições, expõe-se enquanto disciplina da construção, da criatividade que constrói e que faz funcionar o que constrói; um impressionante território artificial, volumoso, comportando diferentes níveis, repleto de superfícies transparentes mas também de pórticos, paredes planas, opacas, de cúpulas ovoides, de cabos, de hangares, de rampas, de trípodes, de colunas; um objeto que paira autónomo, intacto, completo (assim o aparenta) sobre um deserto frio, desarborizado, seco, sem cursos de água, sem relevo; mas do lado de dentro a arquitetura desincorpora-se da ideia de edifício, da ideia de perenidade, regressa ao seu primitivismo, regressa à experimentação, ao heteróclito, 
dissocia-se da homogeneização visual e do controlo social que lhe é concomitante; no interior a arquitetura especula, é a arte, na definição de Bataille, ${ }^{10}$ que se manifesta desfazendo, extraindo, libertando, desimpedindo, desclassicizando-se, despoliciando-se. A circulação não premeditada, a desorientação, a cultura do rendez-vous, do acaso objetivo, o labirinto como a informalidade deste viver diferente, antifuncionalista, soma de fragmentação mas também de associação, transportam-nos para esta hipótese de leitura, para colocarmos, por exemplo, o labirinto de Giacometti como um dos inquilinos do imenso espaço indefinido da Nova Babilónia.

O projeto de Constant como que ignora em nome da progressão do tempo e do culto da alteridade aquilo que constitui a expansão estática, constante, e centralizada da cidade da civilização industrial, da cidade dos homens constrangidos a ficar e a demorar a sua vida no mesmo lugar e nos mesmos trajetos. Constant define dois momentos vitais no quotidiano da urbe que projeta, o assentar arraiais e o levantar acampamento; a casa, a organização doméstica, já não é um sólido fixo num determinado local mas um estado de espírito migrante, e é esse espírito que faz o lugar, que o condensa e o suspende. No contexto das crenças situacionistas o futuro reserva à família a sua extinção. As relações de parentesco deixam de constituir a etapa primordial das relações comunitárias. O habitante do espaço será um desenraizado, não só destituído de uma unidade estável de permanência como de uma infracomunidade com que possa negociar a sua identidade e ancorá-la numa genealogia e numa psicologia, a família. Esta metacidade estava com efeito profundamente embebida na itinerância situacionista: o seu eixo principal seria horizontal, um traçado excursivo vocacionado para o desaparecimento do carácter privado da ocupação e existência espacial; substituir-se-ia a ocupação pelo movimento livre, a concentração pela dispersão, a mobilidade social (a experiência da cidade segundo os critérios da racionalidade e do individualismo burguês) pela mobilidade situacionista (a experiência que eliminasse a cidade como controlo social e a tornasse o espaço de criação de situações). A atmosfera parece fantasmagorizar a forma tornando-a mais vulnerável, mais vagabunda. Os espaços não se fecham, não se diferenciam, já não são uma concentração de matéria, estilo e função num ponto geométrico, nem enclaves de convenções e de isolamento mas adaptam-se, tornam-se flexíveis; já não se adaptam à exceção cultural que são as formas de vida estática, a automatização da vida, mas a uma existência material que tem em seu poder técnicas de mudança cruciais, quer ao nível da vida física como

${ }_{10}$ Sobre o tema da cidade vulnerável e antivisual consulte-se Yve-Alain Bois e Rosalind Krauss (1996: 55-70). 
também da vida psicológica e cultural, e que as quer aplicar intensamente, que deseja antecipar para o quotidiano presente a promessa de que o trabalho não-criativo, a monotonia, o sempre-igual, a ética do trabalho-recompensa já não fazem parte da vida coletiva. É nesse sentido que o espaço social constitui o espaço fundamental do urbanismo unitário e por consequência, afirma-o Constant, do seu projeto de cidade. ${ }^{11} \mathrm{~A}$ rua ampliada numa imensa superfície fechada, ventilada, dispondo de ar-condicionado e suspensa por cima do tráfego automóvel, libertaria o indivíduo do colete de forças jurídico que é a sua condição pedonal na cidade moderna. Não é só uma questão de ganhos acrescidos de tempo livre, mas de ganhos no que respeita ao uso do espaço, à livre deslocação (ao fim da ditadura da intermitência walk-don't walk), ou seja, a um estilo de vida que para se deslocar de um ponto $A$ a um ponto B da cidade não encontra obstáculos, barreiras, impedimentos legais, interpelação e repressão policial, fronteiras, burocracia, portas fechadas, muros e arame farpado.

No antifuncionalismo e descontextualismo do projeto de Constant há o desejo (talvez inconsciente) de um "polimento e policiamento dos costumes"; essa talvez seja uma das fraquezas que se vê refletida no facto de esta cidade virtual estar em conflito mas também hesitante em relação à cidade real; ela opõe a sua narrativa em aberto, otimista mas incompleta, ao desconcerto da experiência fragmentada e casuística da cidade viva. A psicogeografia acumulada ao ponto em que se torna cidade possui implicações distópicas. Como Willemijn Stokvis observa no seu estudo sobre o movimento CoBrA, o próprio Constant denota esse mal-estar (Stokvis, 1987: 23). Nas pinturas onde representa fugazmente a gestalt da sua cidade-edifício pressentimos a sensação de incompletude. A urbe neófita como que é desacreditada pelo clima visual de espetáculo cancelado com que é presentificada. Nas suas pinturas não há assim tanta alegria neste mundo artificial. O sombrio taciturno, a atmosfera decadente, inóspita do fim de festa são bem mais percetíveis. E a imperfeição e o grotesco parecem enregelar o quotidiano. E, sim, nesta incubação benigna entrariam os ingredientes da sua distopia, da sua reconversão em realidade mutante e em quotidiano sombrio: até o personagem ignóbil dos Cadernos do subterrâneo de Dostoyewsky poderia "mostrar a língua" a este "palácio de cristal"; até o sofrimento e o desejo teriam direito a ocupar espaço. Mesmo a vida feia, medíocre, a sombra profunda da multidão, os indivíduos desintegrados, acabariam por entrar, por se instalar no meio desta comunidade, e por, em determinadas

${ }^{11}$ Constant (apud Wigley, 1998: 134), Unitary Urbanism, manuscrito de uma conferência realizada no Stedelijk Museum Amsterdam, em 1960. 
circunstâncias, tomar as rédeas do protagonismo público; sim, esta sociedade bela, renascida, acabaria por ingressar no caminho imperfeito, dorido, sofrido da revolução; acabaria por se autonegar se quisesse sobreviver, se quisesse continuar. Mas é exatamente esta conceção expressionista do estar e do agir neste ambiente artificial em forte contraste com a natureza enfática, high-tech, do seu rosto mais verosímil, o arquitetónico, que acentua o carácter cinético, metabólico do seu projeto e o seu valor histórico. É essa dúvida, encarnada na descontinuidade sincrónica do construído, que não se pressente nas utopias arquitetónicas, construídas ou não, do século Xx, da Ville Radieuse à Fordlandia, de Levittown a Gropiusstadt e que garante que o projeto sobrevive ao policiamento do seu demiurgo. É a incerteza, o sinal de alarme de que também aqui as coisas podem correr mal, que a entropia, a desordem, o imprevisto, a tragédia se podem tornar inquilinos indesejáveis, é ela que torna ainda mais significante esta investigação. Os desenhos e os cenários de fundo de muitas das pinturas onde reaparece o sonho urbano de Constant são reflexo, talvez, de que na sua personalidade havia um bater do coração para a condição humana, para a afirmação e construção da subjetividade, que se diferenciava do bater do coração em relação às tarefas de organização espacial da experiência humana: a construção não cairá mas a humanidade pode falhar, é necessário que a humanidade incorpore a possibilidade do erro na sua genealogia, que o use como um antimonumento dissuasor de qualquer cristalização do edifício utópico por via de uma falsa perfeição social. O edifício utópico é uma máquina sem lágrimas, mas tem que incorporar a experiência do sofrimento, do incompreensível, do estranho, só assim pode escapar à indiferenciação entrópica dos valores; só conhecendo o mal, praticando o mal, desejando o mal é que a arte pode salvar a vida das suas imitações e impedir que se concretize na utopia construída o cinismo de Bouvard e Pécuchet de que "nada é verdadeiro a não ser os fenómenos". Esse primeiro bater do coração de que falávamos, essa consciência do outro, mesmo que ele seja o arauto da barbárie e da privação constitui, aliás, um sintoma de que na Nova Babilónia estamos diante de uma das formas históricas do modernismo onde se conservam porções inescapáveis da mesma indecisão diletante e para-romântica, da mesma antinomia entre revolução e autocrítica. ${ }^{12}$

Num texto de 1970, vinte anos depois de iniciar o seu compósito de desenhos e maquetas, Constant escreverá:

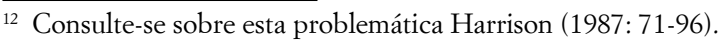


A Nova Babilónia talvez não seja tanto uma imagem do futuro mas um leitmotiv, a concepção de uma cultura que abrange praticamente tudo e que é difícil de compreender porque até agora não podia existir, uma cultura que, pela primeira vez na história, como consequência da automatização do trabalho torna-se concretizável se bem que nós não saibamos ainda que forma tomará, e permaneça por isso ainda misteriosa para nós. ${ }^{13}$

Praticamente no final do seu percurso criativo que se concluiria em 1974, Constant como que nos diz que colocou o pé em terra firme, descobriu um novo território mas desconhece qual é a sua escala e o seu alcance. Esse sentido dilatório e impreciso deve ser uma âncora conceptual da Nova Babilónia, para que ela possa permanecer como posteridade. "Transformar o mundo [...] vagueando por aî" (Guy Debord apud Jappe, 2008: 65), eis uma das teorias sociais presentes no projeto de Constant. A Nova Babilónia surge então como um enlace quotidiano entre o mudar de vida e o transformar o mundo, os slogans reprimidos da história humana. Charles Baudelaire afirmava que a temporalidade dilatada que o homem moderno conquistou, a ociosidade, também se preenchia com a conceção lúdica de fantasias arquitetónicas. Constant praticamente cem anos depois proporá um veículo de unidade tectónica (a máquina bela e sem lágrimas, pelo menos lágrimas morais) onde se organiza o divergente, o não relacional; onde os mitos e o simbolismo dos indivíduos específicos não existem em conflito mas em comunidades adjuvantes; um lugar mais do que uma representação totalitária de espaço onde se torna viável a multiplicidade de espaços de representação. Demostrando-nos com essa experiência que a arquitetura é, de entre todos os subprodutos da eternidade, o único que não se pode dar ao luxo de ser superior e exterior à vida e que nela também estão inscritas as palavras de Benjamin Péret:

Parece aliás que do esforço de emancipação dos homens antes de mais nada subsistem os holocaustos oferecidos a essa libertação, nos quais figuram as aspirações de uma época inteira. É como se os oprimidos dissessem às gerações chamadas a suceder-lhes: "Nós perecemos porque nos enganamos. Procurai saber onde reside o nosso erro". (1988)

Parafraseando o desafio de Friedrich Engels sobre a Comuna de Paris, terminamos perguntando-vos: quereis saber que rosto tem a utilidade de

13 Constant (1970), New Babylon: The World of Homo Ludens. Consultado a 12.02.2011, em http://www.notbored.org/homo-ludens.html. 
uma arte que não está prisioneira do passado nem é servil ao presente, uma arte que é útil porque transgressiva e transgressiva porque mantem invisível o seu sentido? Olhai a Nova Babilónia.

\section{Referências bibliográficas}

Aragon, Louis (1982), Le paysan de Paris. Paris: Gallimard.

Apollinaire, Guillaume (2008), O heresiarca \& $C^{a}$. Lisboa: Assírio \& Alvim.

Attlee, James (2007), "Towards Anarchitecture: Gordon Matta-Clark and Le Corbusier". London: Tate Papers Issue 7. Consultado a 15.01.2012 em http://www.tate.org. $\mathrm{uk} /$ research/publications/tate-papers/towards-anarchitecture-gordon-matta-clark-and-le-corbusier.

Barthes, Roland (1979), Sade, Fourier, Loiola. Lisboa: Edições 70.

Barthes, Roland (2002), Comment vivre ensemble, Cours et séminaires au Collège de France (1976-77). Paris: Traces Écrites, Seuil Imec.

Baudelaire, Charles (1996), Les fleurs du mal. Paris: Gallimard.

Boersma, Linda (2005), entrevista publicada na Bomb Magazine \#91. Consultado a 20.01.2012, em www.bombsite.com/issues/91.

Bois, Yve-Alain; Krauss, Rosalind (1996), "A User's Guide to Entropy”, October, 78, 38-88. Breton, André (1994), Poemas. Lisboa: Assírio Alvim.

Habermas, Jürgen (1987), “A modernidade. Um projecto inacabado?”, Crítica, Revista de Pensamento Contemporâneo, n. . 2, novembro. Lisboa: Universidade Nova, 5-23. Harrison, Charles (1987), "Le modernisme: aux limites", Cabiers du MNAM - Après le modernisme, 22, 71-96.

Heynen, Hilde (1996), "New Babylon: The Antinomies of Utopia", Assemblage, 29, 24-39.

Jappe, Anselm (2008), Guy Debord. Lisboa: Antígona.

Kopp, Anatole (1990), Quando o Moderno não era um estilo mas sim uma causa. São Paulo: Nobel: Editora da Universidade de São Paulo.

Krauss, Rosalind (1994), The Optical Unconscious. Cambridge, Massachusetts: The MIT Press.

Lefebvre, Henri (1972), Le droit à la ville. Paris: Editions Anthropos, Collection Points.

McDonough, Thomas (2001), "Fluid Spaces: Constant and the Situationist Critique of Architecture", in Catherine de Zegher e Mark Wigley (orgs.), The Activist Drawing: Retracing Situationist Architectures from Constant's New Babylon to Beyond. New York: The Drawing Center.

Nancy, Jean-Luc (1999), La ville au loin. Paris: Mille et une nuits.

Péret, Benjamin (1988), O Quilombo de Palmares. Crónica da "República de escravos" do Brasil, 1640-1695. Lisboa: Fenda. 
Richta, Radovan (1973), Revolução científica e técnica e transformações sociais. Porto: Textos marginais.

Stokvis, Willemijn (1987), Cobra: An International Movement in Art after the Second World War. Barcelona: Ediciones Polígrafa, S.A.

Vidler, Anthony (2001), "Diagrams of Utopia”, in Catherine de Zegher e Mark Wigley (orgs.), The Activist Drawing: Retracing Situationist Architectures from Constant's New Babylon to Beyond. New York: The Drawing Center, 83-91.

Wigley, Mark (1998), The Hyper-Architecture of Desire. Rotterdam: Witte de With, Center for Contemporary Arts.

Wigley, Mark (2001), "Chronology”, in Catherine de Zegher e Mark Wigley (orgs.), The Activist Drawing: Retracing Situationist Architectures from Constant's New Babylon to Beyond. New York: The Drawing Center, 139-149. 
